\title{
FROM PADDY FIELDS TO SUSTAINABLE TOWN IN FOUR DECADES: TIGHT INTEGRATION OF URBAN PLANNING AND PLACE MANAGEMENT IN YUKARIGAOKA, JAPAN
}

\author{
Marco CAPITANIO (iD ${ }^{1, *}$, Sidh SINTUSINGHA (D) ${ }^{2}$ \\ ${ }^{1}$ Faculty of Science and Technology, Keio University, 3-14-1 Hiyoshi, Kohoku-ku, Yokohama, \\ 223-8522 Kanagawa, Japan \\ ${ }^{2}$ Melbourne School of Design, The University of Melbourne, Victoria, Australia \\ Received 07 May 2021; accepted 05 November 2021
}

\begin{abstract}
Private real estate developers disproportionately focus on spatial planning and short-term returns, often forgetting the crucial role played by place management toward the achievement of sustainable communities. This research presents an alternative model of privately initiated urban development: Yukarigaoka, a new town in the eastern outskirts of Tokyo founded in the late 1970s. The case study has been analyzed through field research, assessments of local media, interviews and literature review, focusing on urban planning strategies and place management practices. Yukarigaoka is a non-speculative model entailing the developer's long-term commitment to the creation of a community sustained by unique planning features and innovative, award-winning place management practices. As a result, the development avoided the demographic imbalance of many Japanese public new towns of the same period. Population has been constantly growing and the town has been attracting families, strengthening local engagement and a defined identity. Despite a degree of paternalism in approach and the mediocre design quality of the built environment, Yukarigaoka confirms that livable communities result from the tight integration of planning and management. It provides an important planning and management precedent for new and existing communities in other Asia-Pacific cities toward establishing a synergistic relationship between built and natural components and in advocating for long-term profit different from a predominantly neoliberal developmental model that maximizes immediate returns.
\end{abstract}

Keywords: sustainable development, urban planning, participative place management, privately developed town, sufficient profit model, livability, Yukarigaoka.

\section{Introduction}

The neoliberal approach to urban development (see Aalbers, 2013) treats housing as an investment asset resulting in increased social inequities, deterioration of quality of life, and the loss of valuable arable land. In the Asia-Pacific region, this approach was explicitly manifest over the past three decades in the phenomenon of sprawling, car-oriented, speculative suburban developments such as Muang Thong Thani (MTT) in Bangkok (1987), Roxburgh Park in Melbourne (1992), Linh Dam in Hanoi (1997) (Sintusingha, 2008), and Phu My Hung New Urban (PMH) in Ho Chi Minh City (1993) (Huynh, 2015).

As a reaction, sustainable development has been focusing on a range of spatial approaches: polycentrism, intensification, investment in mass transit infrastructure, "smart cities", retrofits, etc. However, these efforts have been disproportionately focused on urban spatial planning, neglecting the role played by place management in the creation of livable communities.

Are there examples of alternative developmental models - whether public, private or a combination of both that integrate from the outset the planning and the management sides of development? If we agree that "the ultimate goal of places is not financial success but the welfare and satisfaction of their residents" (Insch \& Florek, 2008, p. 146), is it possible for a developer to make profit while being engaged in long-term area management without impinging on liveability?

Yukarigaoka - a town in the eastern outskirts of Tokyo founded in the late 1970s - offers an alternative practice, serving as a referential model for the development of new suburban communities or to the management of existing ones. Over the years, Yukarigaoka has been able to

${ }^{*}$ Corresponding author. E-mail: capitanio@keio.jp 
counterbalance the population shrinkage and infrastructural decline, typical of Japanese suburban areas, due to the planning and management strategies of its developer (Uemura, 2019; Nikkei Keizai Shinbunsha, 2019, pp. 191-201; Kodama \& Nakano, 2016; Brasor \& Tsubuku, 2016; Nihon toshi Keikaku Gakkai, 2011, pp. 150-153; Seki et al., 2002).

Three main characteristics set Yukarigaoka apart when considered against the context of shrinking peripheral areas in Japan: first, its population has been continuously growing since its inception; second, it has been privately developed and managed over a long time-span - contrary to the majority of publicly-initiated new-towns of the period; third, it features innovative and unique urban planning and place management practices, introduced in more detail in the following sections.

From a planning point of view, Yukarigaoka makes the invisible agricultural and ecological context visible and a part of everyday life, integrating "ecological functions into the cultural perceptions of nature" (Nassauer, 1998, p. 161). This is achieved by avoiding the common practice of treating rural land as a palimpsest to be erased - anticipating regulatory changes in Japan discussed later in the paper. This contrasts with other Japanese new towns of the period - in Tama New Town, the largest public development in Japan to date, entire hills were flattened (see Capitanio, 2018b) - or with prominent international newtown experiments, such as Radburn, New Jersey where "[f]ew remnants of the borough's agricultural past remain" (Lee \& Stabin-Nesmith, 2001, p. 153). To put these features in context, $\mathrm{Du}(2015$, p. 134) remarks, in relation to the PMH project in Ho Chi Minh City, that the development entails "serious concerns on urban sprawl, segregation and environmental issues", while Phnom Penh's 90ha Beung Kak lake - home to a fishing community and a source of fresh water for the city - has been reclaimed in its entirety between 2008 and 2012 (Baliga \& Chakrya, 2017) to make space for the eponymous development project.

From a place management perspective, even though in the 1950s and ' 60 s there were other successful privatelydeveloped towns, ${ }^{1}$ Yukarigaoka stands out due to its peculiar form of area management, focused on a long-term period and featuring the collaboration of the developer and the inhabitants. Through an elaborate form of topdown and bottom-up interaction and branding practices, Yukarigaoka has been able to craft a distinctive identity and a positive reputation.

We posit that the tight integration of tailored planning strategies with long-term place management is effective toward the creation of sustainable and resilient communities. From the outset, the developer of Yukarigaoka applied - whether consciously or not - the "triple bottom line" in its long-term management of economic, social and environmental concerns, despite certain caveats and limitations that we will explore in the conclusions.

\footnotetext{
1 Such as Reston, Virginia. See Forsyth and Crewe (2009) for an assessment of three American and British new towns.
}

The paper starts with a historical review of the town's inception and evolution, focusing on the developer's founding initiatives and rationale. It proceeds with the analysis of the town's urban plan and its morphological characteristics, followed by an assessment of place management practices, and concludes with a discussion on the international relevance and transferability of the Yukarigaoka case.

\section{Methods}

From a methodological standpoint, the research assumes that sustainable development and livability are about " $d e$ signing and managing the places where people choose to live and work" (Knox \& Mayer, 2009, p. 24, our italics). The paper thus focuses on one case study, assessing its urban planning and place management characteristics.

The urban planning assessment relies on the methodological framework devised by Capitanio (2018b), analyzing four factors - relating to urban morphology - deemed to be fundamental in understanding the spatial characteristics of a neighborhood: density/compactness, diversity of uses, walkability and green/water space. The observations, collected through three full-day site visits in different seasons, were graphically elaborated against publicly available GIS data of the area.

The place management assessment relied on a range of primary and secondary sources: background research of relevant literature in Japanese language relating to Yukarigaoka; reviews of local publications, the town's web portal and developer's reports, complemented by an in-depth interview with a Yamaman representative on-site. To assess Yukarigaoka's planning and management practices we examined the morphological qualities of the town, both quantitatively and qualitatively. We then reviewed adopted place management practices and their degree of success, with a specific focus on branding and participatory aspects. The paper does not focus on the analysis of residents' preferences and degree of satisfaction, aspects crucial in determining the degree of livability of an area. Future development of the research shall tackle this aspect.

\section{Inception and growth of Yukarigaoka}

Yukarigaoka (ユーカリが丘) is a privately developed district spread over 383 ha in Sakura City, Chiba Prefecture. It lies ca. $35 \mathrm{~km}$ ( 60 minutes by train) east of Tokyo Station and has a population of ca. 18,500 as of 2019, about one-ninth of Sakura City (Motani, 2014, p. 187-219). Land prices in 2018 ranged between 65,000 and 120,000 yen/sq.m (600 to 1,100 USD/sq.m) (Lifull 2019) far below the 2018 average residential land price in Tokyo Prefecture of 342,600 yen/ sqm (Statistics Japan, 2018). This makes housing prices in Yukarigaoka affordable by Tokyo's standards.

The new town has been developed by Yamaman (山万), a listed company (with a current capital of ca. 270 million USD) founded by Tetsuo Shimada in the 1950s. Shimada intended to develop a town different 
from large publicly initiated new town models. Japan had been facing a housing shortage due to the rapid economic growth following WWII, to which the government responded with large public-housing schemes in the form of 5- to 11-story apartment blocks at the fringes of large conurbations - with Tama New Town as a prime example. In line with the raised ecological awareness of the 1970s in Japan, Shimada envisioned instead a family-friendly residential environment for up to 30,000 people. He selected an area in Sakura City, close to the Inba swamps, between the center of Tokyo and Narita Airport, negotiating land acquisition from local farmers over a period of three years.

With a focus on public transportation, the core of Yukarigaoka was planned on consolidated land around a station. The developer implemented an internal transportation system with the construction of a monorail with six stations, ensuring that each household lies within a 10-minute walk to the nearest station. In plan, Yukarigaoka resembles a doughnut clustering around the monorail, linked to the Keisei railway line to the south (Figure 1). This was the first time in Japan that a private real-estate developer came to manage a railway line - reflecting the developer's long-term vision in the capital-intensive infrastructural investment.

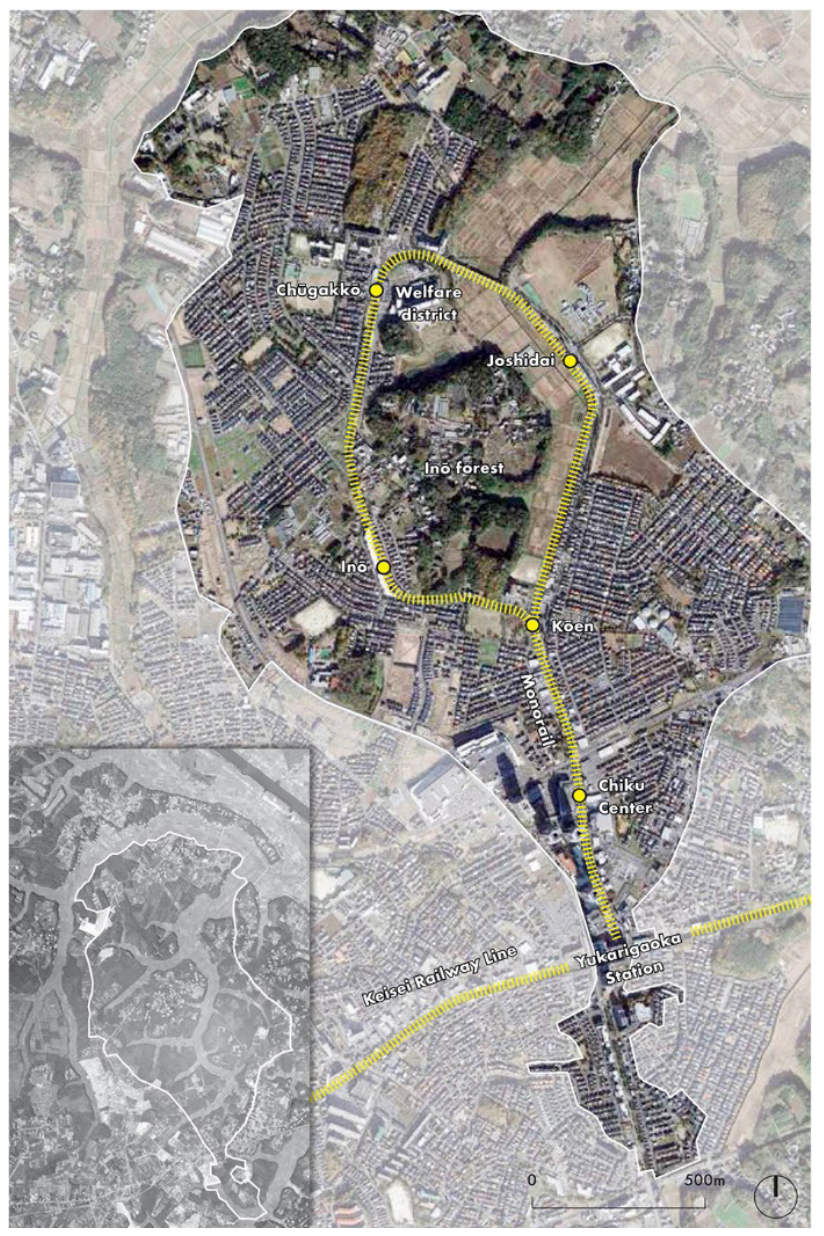

Figure 1. Case study area and its immediate surroundings. At the bottom-left inset, an aerial image of the area in 1966
The planning is characterized by the retention of a $s a-$ toyama ${ }^{2}$ (Ino Forest) - comprising a rural village, forest, farmland, shrines and a temple - at the center of the masterplan, designated as land not to be developed. The initiative fits with the Productive Green Land Act, enacted in 1974, that significantly reduced land property inheritance taxes for farmers, thus helping to retain productive agricultural uses in urban areas. The area close to Yukarigaoka Station was planned as a more urban environment, with high-rise residential condominiums, commercial and mixed-use buildings.

The project began in 1971, construction started in 1977, and the first residents moved-in in 1980. Yukarigaoka Station opened in 1982, when the monorail service started operations. Crucially, instead of developing and selling as many units as possible in a short timeframe, the developer opted for a long-term strategy. Yamaman would sell around 200 houses per year, foreseeing to infill all plots in 40 years, a policy that has been followed with remarkable consistency as it can be seen by the population graph (Figure 2).

Yamaman realized that, if many inhabitants of the same cohort move-in at once, a demographic imbalance would undermine future livability, as indeed happened in most new towns across Japan. As an example, between 2008 and 2017, the number of children in Yukarigaoka increased by $53 \%$, whereas it decreased by $13 \%$ in Sakura City as a whole, and decreased by $41 \%$ in Tama New Town between 1980 and 2015 (Figure 3).

As the community grew during the 1980s and ' 90 s, the area gradually expanded and added new services, such as schools, a post office, a police station, community center, department stores, Wakayama Women's University annex, an NHK (national broadcasting network) cultural center. The area around Yukarigaoka Station consolidated as a hub, hosting a hotel (managed by Yamaman) and a cinema.

Reflecting the evolving demography, starting in the 2000s Yamaman revised its business model focusing on elderly-care and child-rearing. It created a 15 ha healthcare hub to the north of the town, constituted by geriatric

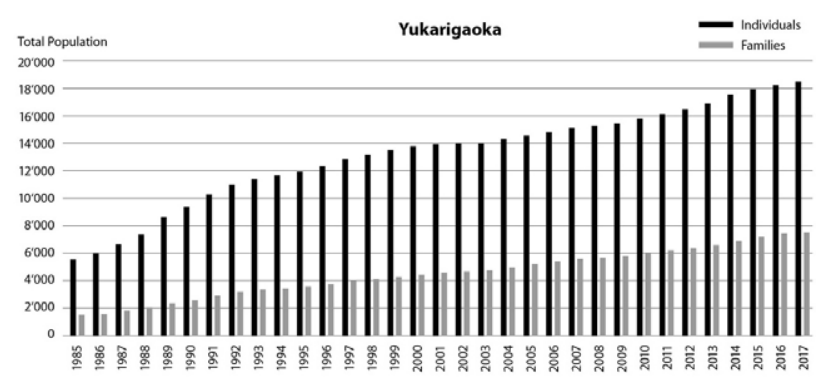

Figure 2. Population of Yukarigaoka between 1985 and 2017

2 Combining the characters of "countryside" and "mountain" (里山), satoyama is the area marking the transition between hills or mountains and arable flatland. This border zone usually hosts forests and cultivated fields, important ecosystems endangered by urban development. 


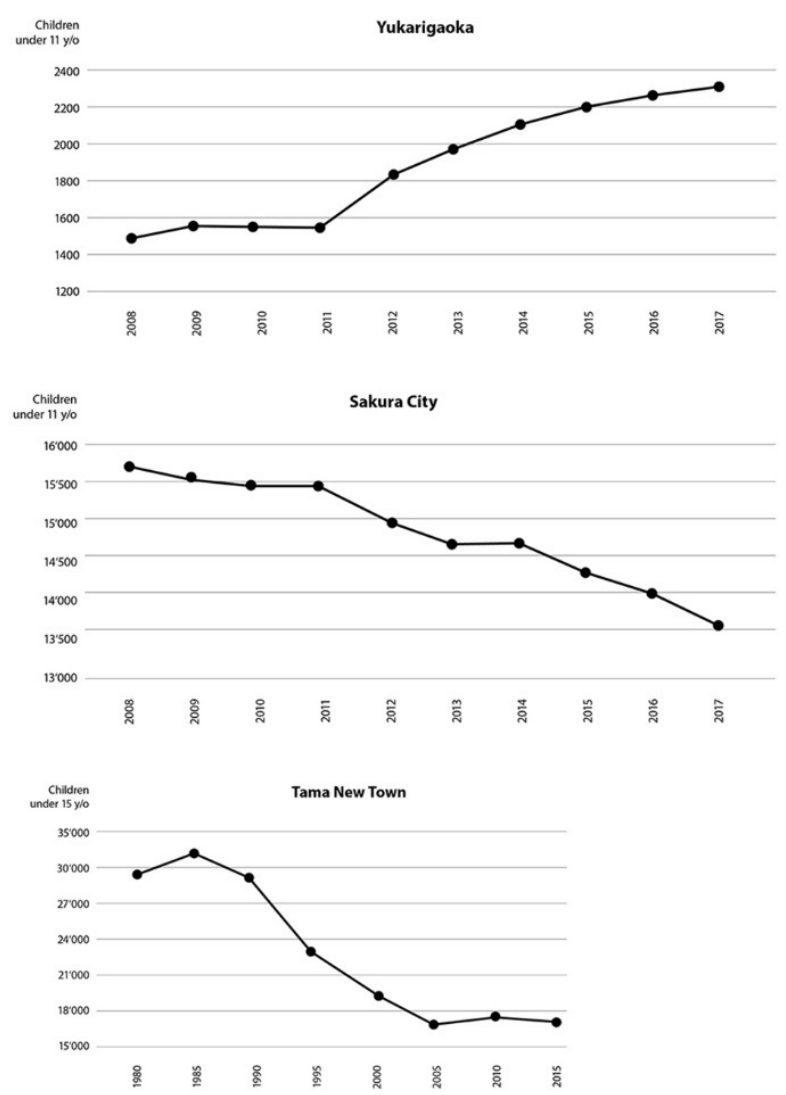

Figure 3. Percentage of children up to $11 \mathrm{y} / \mathrm{o}$ in Yukarigaoka and Sakura City and up to 15y/o in Tama New Town over the years

institutions, elderly housing, a biotope with a therapeutic garden and an integrated facility for the elderly and children. Between 2004 and 2016 two nurseries with a capacity for up to 120 children and an indoor play area were opened. In 2005, to address generational shifts and changes in household composition, Yamaman introduced an innovative urban management system, the "Happy Circle" (Yamaman Kabushikigaisha, 2016, p. 7), further discussed in the place management section. All these efforts can be interpreted as measures to sustain profit, in view of the anticipated population shrinkage in Japan, while catering for the changing needs of the residents. In fact, it can be foreseen that municipalities will have to compete to retain population and to potentially attract new residents of younger cohorts to maintain economic and social vitality.

The 2000s and 2010s witnessed increased devolution and share of town-management responsibilities and services to the residents, with the establishment of machi$z u k u r i^{3}$ groups and initiatives of town-promotion. Among other initiatives, community garden allotments were made available for rent, Yamaman Farm was established, and branded tomatoes put on sale. Non-profit organizations (NPOs), life-support services and volunteer organizations

\footnotetext{
3 Literally "town-making", a typical Japanese bottom-up participatory practice (see Capitanio, 2018a).
}

were created. These initiatives could be interpreted as the developer passing on part of its organizational and economic burdens to the residents. However, they also confirm the maturation of the developer-resident interactions and self-initiative capabilities of the residents.

Given the policy of 200 new households per year, the population in the area has been increasing constantly. Only a handful of blocks are still undeveloped at the time of writing. Population is expected to level off and Yukarigaoka's goal will be to retain its inhabitants and ensure the replacement of households. In November 2020, a community bus route was established to complement the monorail line. This move confirms the ongoing attention toward area management and reinforces the role played by public transport in a suburban setting. Moreover, the town is about to commence its first major redevelopment project - the overhaul of the north-side of Yukarigaoka station to be completed by 2030 .

\section{Urban planning assessment}

The density/compactness assessment is summarized in Figure 4. The Spacematrix diagram (Berghauser Pont \& Haupt, 2010) integrates four variables in one chart: the FSI (Floor Space Index, the density or intensity of a settlement); the GSI (Ground Space Index, the compactness of a settlement); L (Layers, the average number of floors); and the OSR (Open Space Ratio, the openness and pressure on non-built land). It indicates a total GSI of 0.15 i.e. $15 \%$ of the case study area is occupied by buildings - a FSI of 0.50 , an OSR of 1.69, with an average number of floors of 3.3. These indicate that Yukarigaoka is a low-rise, spacious development, with a suburban/rural character. Nevertheless, there are pronounced differences within the case study area. Typical residential blocks of detached houses are two times as dense and almost three times as compact as the total average, assuming an urban character. Detached houses are closely built, with a minimum amount of private garden around the buildings. Mixed-use blocks around Yukarigaoka Station are an abrupt contrast to the residential area. They are eight times as dense as the total average and their bulk is typical of highly urban environments. Such contrast is clearly visible in the mapping of building height.

A second exception to the uniform urban fabric is found toward the north of Yukarigaoka: this area, in fact, is a secondary hub, where a junior-high school, elderly housing, a high-rise condominium, a shopping mall and a water biotope are to be found. In the figure-ground plan, the void within the monorail loop and another that corresponds to paddy fields on the north-eastern side of the area are clearly visible. Buildings are generally aligned along the street. The population density is $52.15 \mathrm{pph}$, slightly lower than that of Tokyo Prefecture. ${ }^{4}$

4 Tokyo Prefecture's density was ca. 61 pph in 2015 (Tokyo Metropolitan Government, 2017); however, in the 23 central wards it was ca. $151 \mathrm{pph}$ (in 2015) with a peak density of ca. 330 pph. 

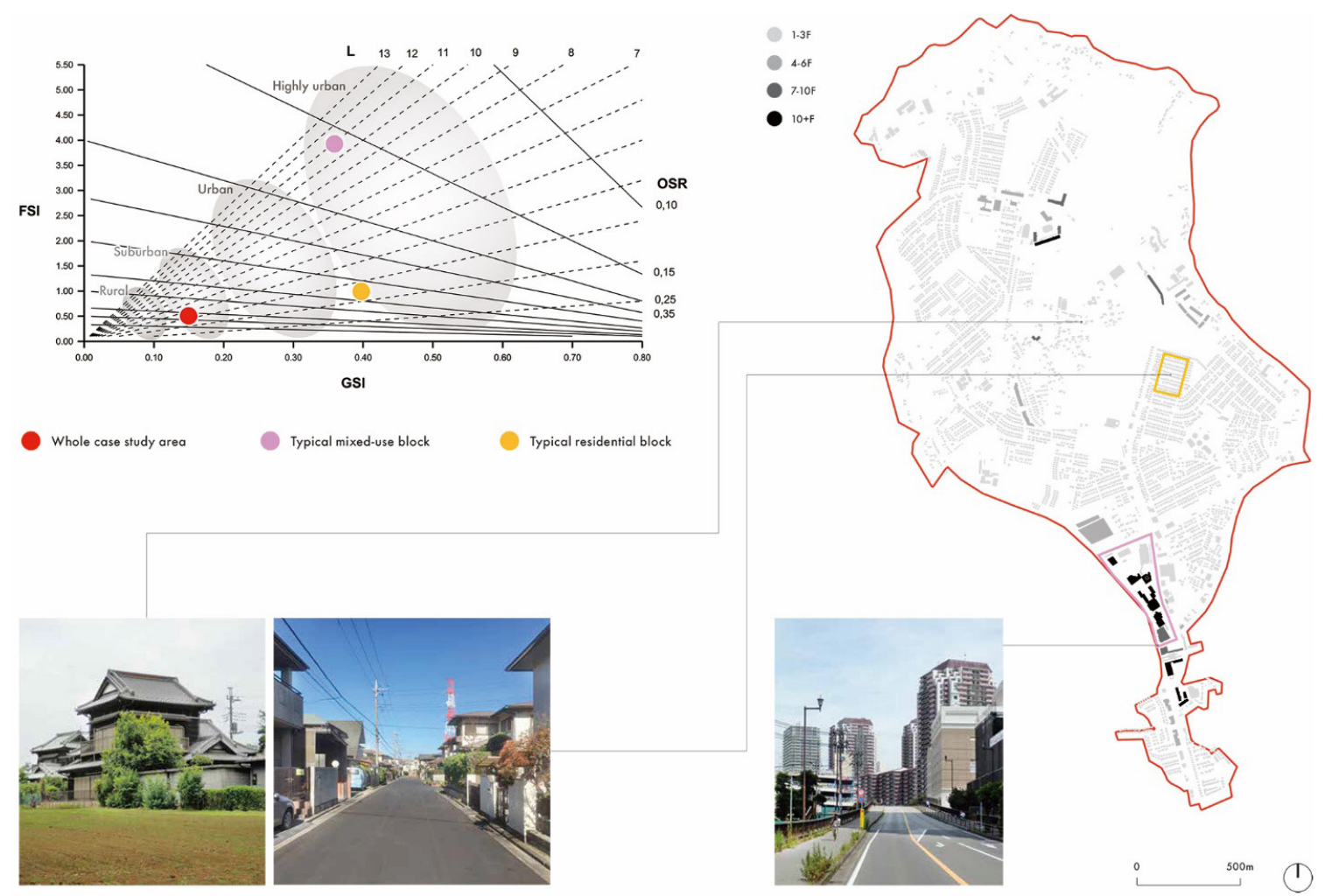

Figure 4. TOP from left to right: Spacematrix diagram; building height map. BOTTOM from left to right: farmhouse beside Inō forest; typical residential area; mid- and high-rise development close to Yukarigaoka Station

The mix of land uses assessment is summarized in Figure 5. First, we quantified diversity of uses both at ground floor (MXI GSI) - where most of pedestrian activities take place - and with regard to the total floor space (MXI FSI). The Mixed Use Index, or MXI (van den Hoek, 2008) is a tripartite system calculating the amount of floor-space devoted to housing, working (e.g. offices and factories) and amenities (e.g. commercial activities and public functions). These functions are represented in a chart by a percentage over the total floor space of the area, thus indicating the degree of mix. It has to be noted that we take here into consideration just built space; greenery and water space are tackled in a separate factor.

At ground level, $74.2 \%$ of built space is devoted to housing. Visiting functions (e.g. shops, public services) occupy $18.3 \%$ of the total ground floor space, while working functions (e.g. offices, factories, workshops) constitute $7.4 \%$. Figures regarding the diversity of uses over the total floor space present similar proportions. By these we understand that the case study is a predominantly residential area with a substantial amount of commercial and entertainment functions. The considerable number of productive activities, mainly represented by farms, greenhouses and workstations confirm the strong link between the new development and existing agricultural practices. Second, we have mapped the spatial distribution of uses. A majority of visiting functions is concentrated, as expected, around Yukarigaoka Station, where the increased density allows for a higher mix of uses. The north-south main road departing from the station can be identified as a high-street forming a coherent shopfront. Other visiting functions are distributed around the whole area, reflecting in part the locations of the five monorail stations (not counting Yukarigaoka Station). Working functions, mainly activities predating the area's development, can be found inside the monorail loop and along the northern edge of the town.

The walkability assessment is summarized in Figure 6. The pedestrian environment was first analyzed with quantitative models and simulations referring to space syntax. Space syntax is mainly used to assess the (intel)legibility of street networks and the accessibility of points (e.g. representing buildings) along given routes. With two betweenness simulations we aimed at predicting pedestrian flows in the case study area, according to shortest paths. For this research, we used the plug-in software "Rhino UNA toolbox" (Sevtsuk, 2016). Among the many types of space syntax analysis, we focused on betweenness, to simulate pedestrian flows, and gravity, to assess shopping accessibility. Betweenness approximates by-passing footfall at particular locations in a spatial network, while gravity 

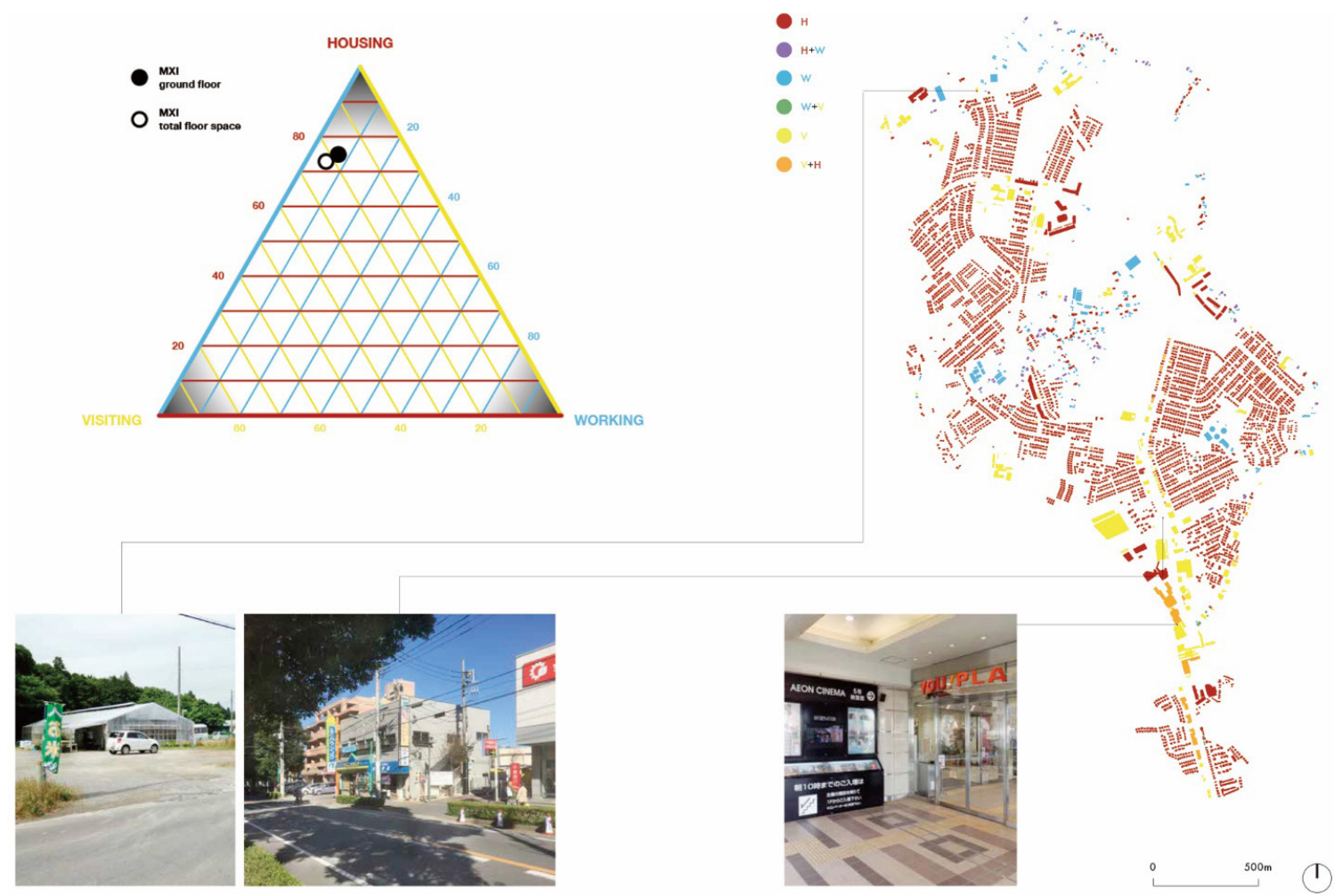

Figure 5. TOP from left to right: MXI diagram; building use map. BOTTOM from left to right: rice farmer selling directly to the general public; high-street departing from Yukarigaoka Station; entrance of shopping mall

measures the number of destinations around each origin within a given search radius and factors in the travel cost required. This analysis indicates how many shops can be reached from each residential building within a $500 \mathrm{~m}$ walking distance, along a given street network (for detailed explanations see Sevtsuk, 2016).

We aimed, with two betweenness simulations, to predict pedestrian flows in the case study area, according to shortest paths. In the first simulation (a), all residential and office buildings represented origins, weighted according to the number of floors, while all six monorail stations represented mutually excluding destinations, so that every origin generated a single route to its nearest station. Routes were calculated according to shortest paths, resulting in a maximum value of 1,624 routes and a minimum of 1 . Pedestrian flow is expected to be at its highest around Kōen Station, the station closest to the highest number of houses. Overall, there is a strong correspondence between the location of stations and residential buildings, as pedestrian flow is evenly distributed within the whole area.

In the second simulation (b), shops represented origins, weighted according to the number of floors, while all six monorail stations represented mutually excluding destinations, so that every origin generated a single route to its nearest station. Routes were calculated according to shortest paths, resulting in a maximum value of 70 routes and a minimum of 1 . In this case, the highest pedestrian flow is predicted to happen around Yukarigaoka and Kōen stations. The subcenter to the north of the area and the high-street leading to Yukarigaoka Station clearly affect this simulation.
On qualitative terms, we observed a low presence of people using outdoor and public spaces, giving the impression of a very quiet suburban area. Consistent with the previous simulations and with the analysis of diversity of uses, people outdoor were mostly found around the monorail stations and their commercial offers. The design quality of outdoor spaces is inconsistent and variegated: there are modernist decks and plazas, difficult to activate and appropriate; pleasant promenades featuring green, porticoes and shops; leftover spaces poorly fitted with urban furniture. Even on Sundays, pedestrian presence was scarce: customers - and residents in general - seemed to rely on cars for their daily errands, and people were mainly to be found indoors. Let us now examine the accessibility of shops.

A gravity analysis was run with a $500 \mathrm{~m}$ radius, indicating a maximum number of reachable shops of 42 and a minimum of 0 . Despite the maximum value being relatively low, a large number of households enjoys fair accessibility to shopping. While the peak of accessibility lies around Yukarigaoka Station, a wide area between Chiku Center and Kōen stations can be considered as convenient for doing errands on foot. The subcenter toward the north of the development is clearly visible and complements the commercial hub to the south. The least-convenient households in terms of shopping accessibility are the ones located at the northern, eastern and western edges of the town, and the ones at the center of the monorail loop.

The green/water space assessment is summarized in Figure 7. Yukarigaoka is ca. $20 \mathrm{~m}$ above sea level. It presents a moderately hilly topography, with a maximum 

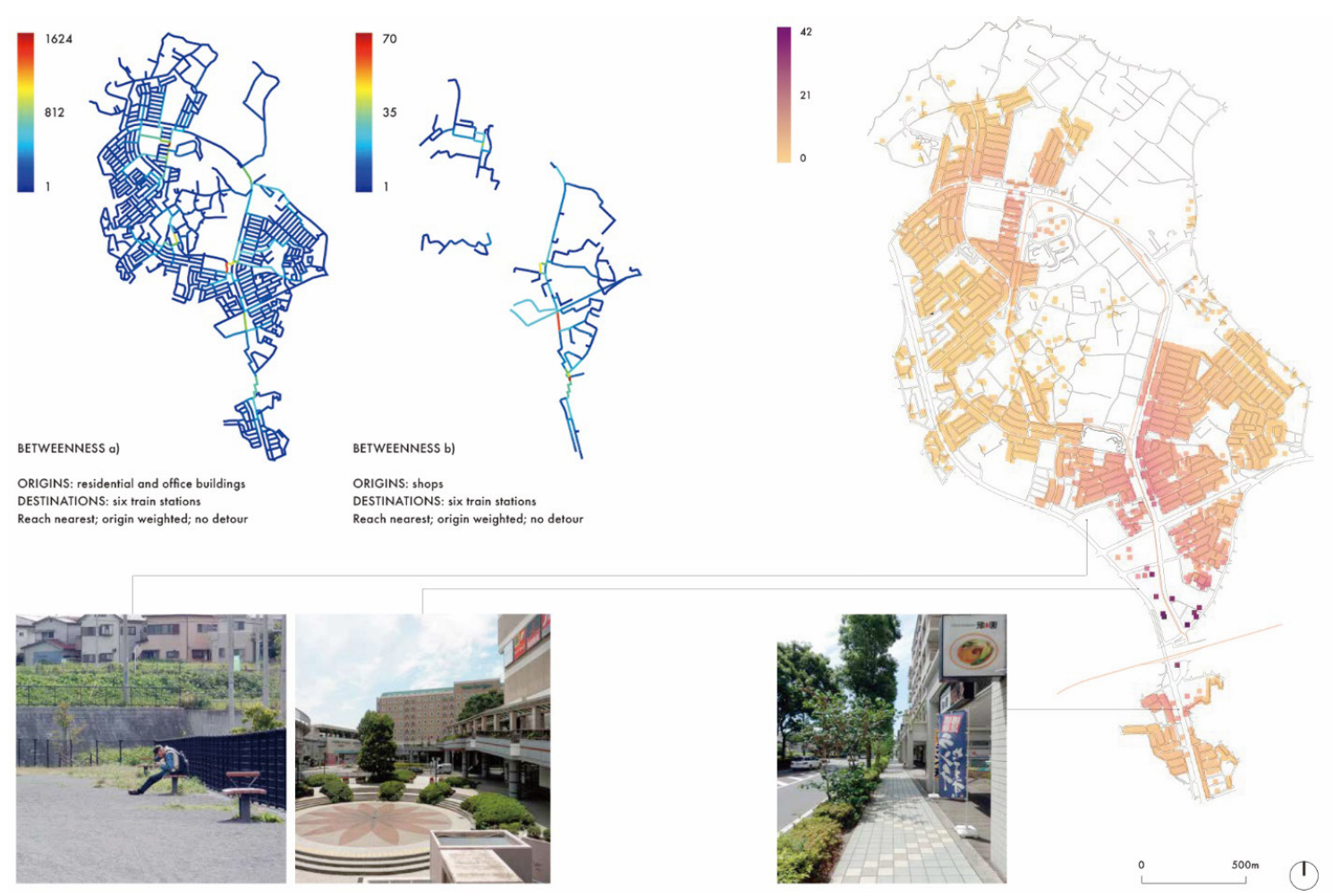

Figure 6. TOP from left to right: two variations of betweenness analysis; gravity analysis. BOTTOM from left to right: nondescript outdoor space beside shopping mall; plaza and elevated deck around Yukarigaoka Station; landscaped high street to the south of the station
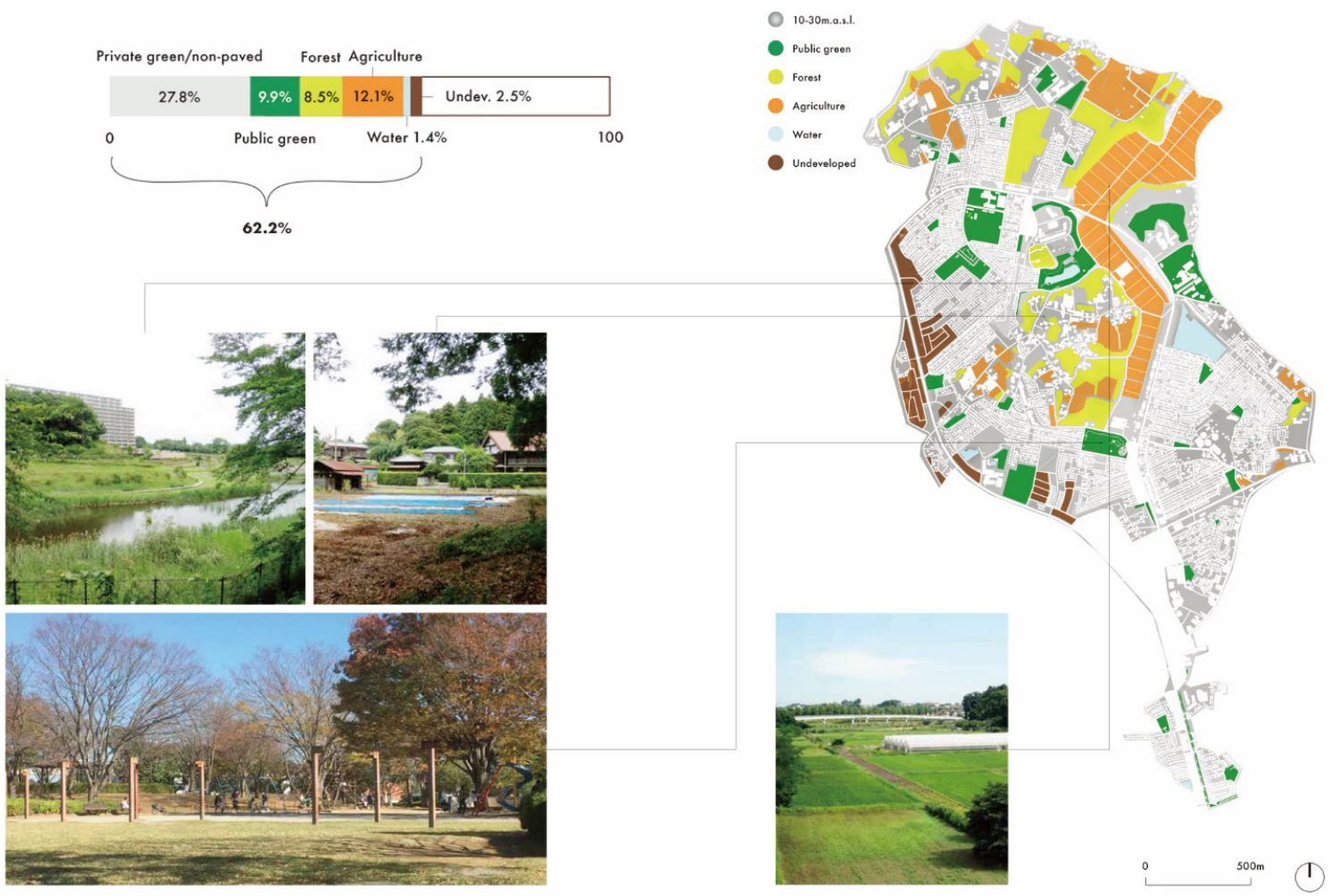

Figure 7. TOP from left to right: amount and type of green/water space; green/water map. BOTTOM from left to right: pond and landscaped area to serve as flood prevention measure; satoyama bordering Inō forest; Minami Kōen on a Sunday; paddy fields 
variation in altitude of $20 \mathrm{~m}$. By examining the terrain's contour lines, it is possible to notice a correspondence between the vehicular and railway network and topographical variations. In fact, the monorail loop runs along a valley, encircling a plateau of sorts, where the Inō forest is located. Paddy fields, forming an S-like strip, are located on low-lying land too, and lead to the Inba swamps towards the north-east. Green/water space in the case study area amounts to $62.2 \%$, and it is mainly constituted by private green and non-paved areas $(27.8 \%)$, followed by agriculture $(12.1 \%)$, public green, i.e. parks $(9.9 \%)$, forests (8.5\%), undeveloped parcels (2.5\%) and water (1.4\%). Yukarigaoka's almost rural character is due to a considerable presence of paddy fields and other cultivated patches (feeding the local farmers market), and to the preserved forested area of Inō and its surroundings. Such presence is relevant both in pure quantitative terms and in experiential terms. In fact, residential blocks are located adjacent to natural environments, while roads and the monorail loop run around and through the satoyama. Yamaman facilitates gardening and small-scale agriculture by providing, since 1998, some 500 allotments at the price of 5,000 yen/year, and establishing in 2015 the award-winning Yamaman Farm, producing tomatoes "made in Yukarigaoka" (Yamaman Kabushikigaisha, 2016).

Given the high amount of preserved natural and private green spaces, the area devoted to public parks is small. There are four main neighborhood parks, which appeared well-maintained and properly furnished. During field analysis, we observed that the largest park - Minami Kōen, beside the homonymous monorail station and the main community center - was well frequented by families and children. We noticed in particular the lack of restrictions regarding playing with balls, stepping on the lawn and the like. At the northern subcenter, Miyanomori Park features a water biotope, which along with other five reservoirs, functions as a retainment pond in case of floods. These ponds are the reason behind a relatively high amount of waterfront space in the area.

\section{Place management assessment}

Yukarigaoka relies on a planned place management system where a combination of top-down and bottom-up initiatives are at work. Through the "Happy Circle" management practice, Yamaman assists homeowners willing to move to another property within the town, buying back their property at full appraisal price. The company then renovates the acquired property before putting it back to the market at an attractive price. "Happy Circle" won the prestigious Good Design Award in 2018, administered by the Japan Institute of Design Promotion (Figure 8). We observe that this practice potentially discourages property speculation and addresses the acute problem of abandoned properties in Japan.

Yamaman established a participative tripartite cooperation system between itself, Sakura City, residents and area managers represented by neighborhood groups. As

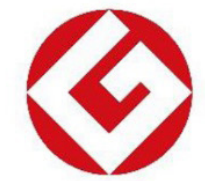

\section{GOOD DESIGN AWARD 2018}

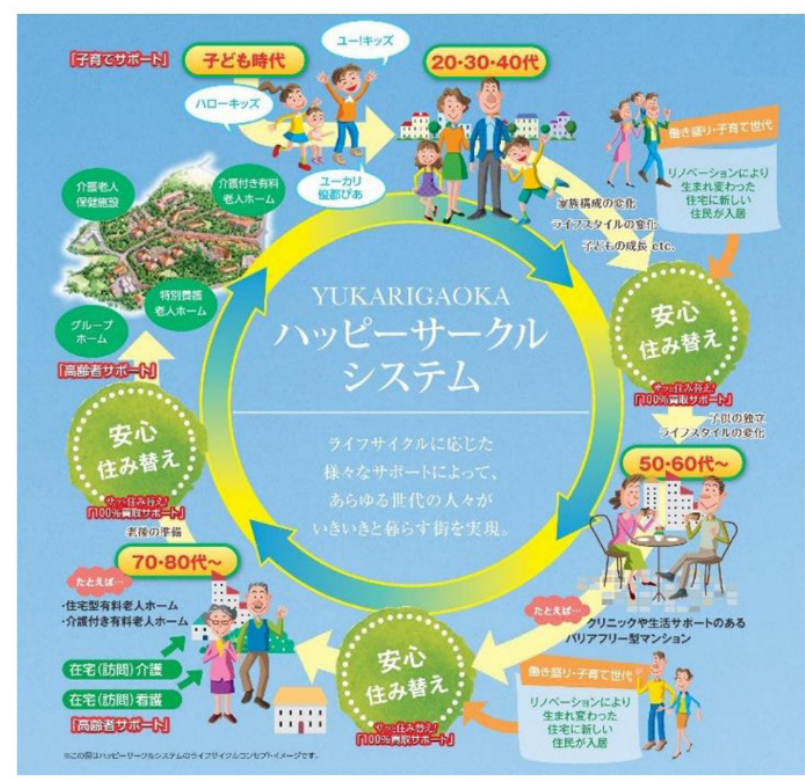

Figure 8. Explanatory diagram of the "Happy Circle" system

Kodama and Nakano (2016, p. 2) put it, "cityscape maintenance and management are harnessed from the residents. [...] Yamaman is not supposed to control everything, but to activate voluntary management by residents of each area" (author's translation).

Bottom-up, self-managed machizukuri groups have been appearing since the 2000s, 20 years after the town's inception. One of the first groups, a crime-prevention volunteer organization, was created in 2000 (Yamaman Kabushikigaisha, 2016, p. 12). A system of area management representative groups commenced in 2009. Their responsibilities range from organizing hearing sessions to address residents' requests to offering life-support services relating to homeownership. Moreover, area management representatives visit each household three times per year, to elicit feedback and provide assistance.

The NPO Yukari Town Network was formed by volunteers living in Yukarigaoka with the aim of contributing to the vitality of the area (Yamaman Kabushikigaisha, p. 61-69). Formed in the late 1980s, the Yukarigaoka Merchants Association - a union consisting of shops and business owners operating within $500 \mathrm{~m}$ from Yukarigaoka Station - organizes four festivals throughout the year (Figure 9). The town's major event, Yukarigaoka Matsuri, held in summer over two days, first commenced in 1983.

Seki et al. (2002) observed that urban management in Yukarigaoka is of a closed type, i.e. only residents can 


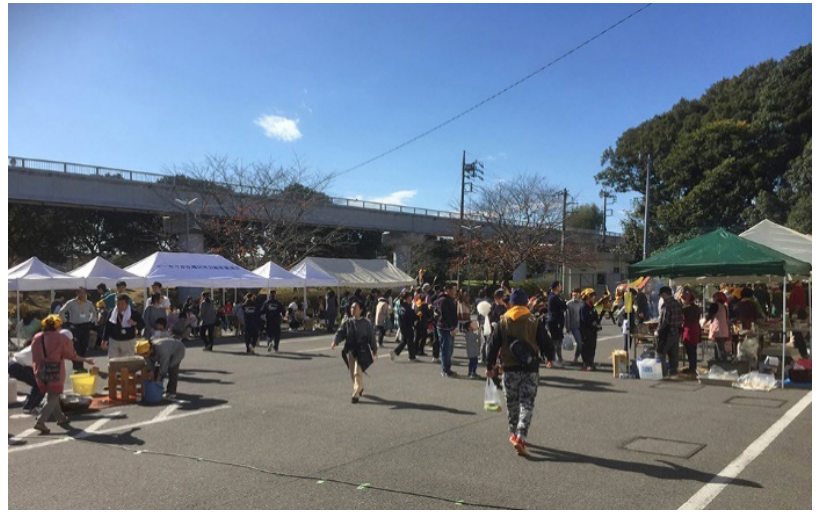

Figure 9. A festival in November 2017

benefit from its various services, upon payment of management fees. This is to be expected in a privately developed and managed town, but it should be noted that it inevitably establishes a dependent relationship between developer and residents. In addition, other volunteer associations operate free of charge in close coordination with Yamaman, akin to a usual neighborhood association.

The reputation of the town has been harnessed starting from its strong link to the natural environment: the combination of residential areas, cultivated fields and forests is a distinctive feature espoused in Yamaman's marketing materials (Figure 10). In this respect, having preserved the $s a$ toyama from the start, the developer seemingly recognized their value and has been able to effectively leverage the existing environmental qualities for marketing purposes.

Built space, on the other hand, is of unexceptional quality. The area around the station and its public spaces are neither memorable nor particularly well-designed. In this respect, the refurbishment of the north-exit environs can be a chance to provide more attractive spaces and more innovative mix of uses. Shrines and temples play an important role as they prevent Yukarigaoka from being perceived as a parvenu development, granting a layer of traditional heritage identity (Figure 11). This is another aspect where Yamaman, by retaining existing structures, has been able to benefit from preexisting conditions.

In a branding and marketing move in 2008, Yamaman opened a gallery and consultation space where a physical model of the town is on display, complemented with a promotional video. The interviewed Yamaman representative took care to mention that, like other Yamaman employees, he lives in Yukarigaoka, implying that he is a stakeholder with a vested interest. We observed this as a case in which word of mouth, marketing and citizen satisfaction are blurred in the purposeful creation of a positive place reputation (see Zenker \& Rütter, 2014; Boisen et al., 2018).

Moreover, Yukarigaoka - despite not being a municipality of its own - has a dedicated information magazine, internet portal, mobile phone application and mascot (a koala bear, true to the town's name of "Eucalyptus Hill"). Since 2014, the Yukari Card can be used for purchases at

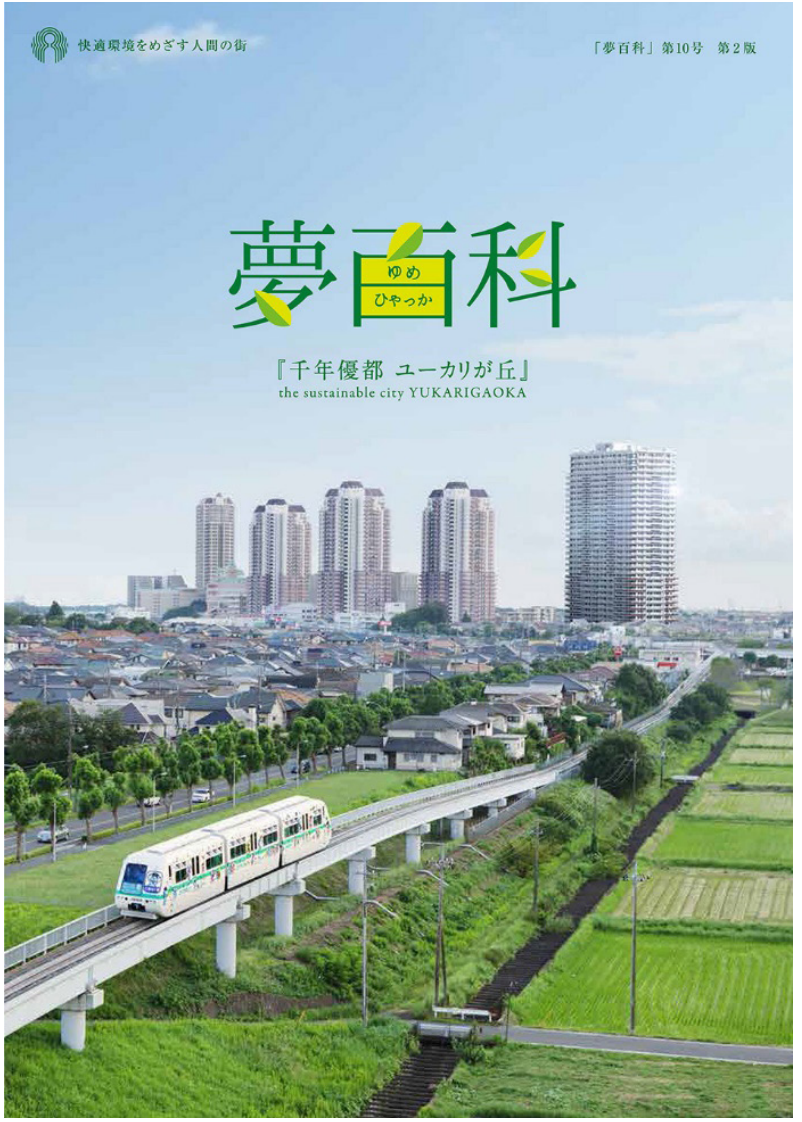

Figure 10. Cover page of Yamaman's promotional brochure

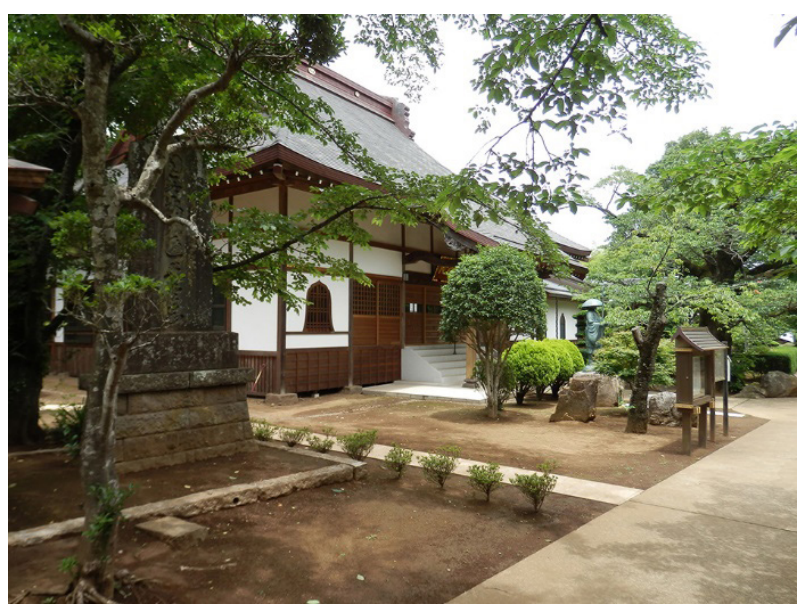

Figure 11. Senjuin Temple became part of Yukarigaoka

local shops and businesses: this is a peculiar case in Tokyo where an area with a strong identity, clear borders and a dedicated management system does not correspond to an administrative entity.

\section{Discussion}

From the point of view of urban planning, the developer adopted an unusual approach for the time: the creation over a long time span of a predominantly residential suburban community featuring public rail mass-transit. 
A second uncommon strategy was the retention of preexisting agricultural practices and natural features and their integration into the whole masterplan, so that the town has been developing around a core composed of preserved paddy fields with patches of forest. The developer, by retaining the pre-existing settlements and maintaining a relevant amount of productive green, could thus harness the economic stimulus deriving from these local businesses. Synergistic advantages were unlocked, as agricultural production has been generating profit, keeping economic diversity and vitality in the area.

In regard to the retention of satoyama landscapes, Yukarigaoka preceded the National Strategy for the Conservation and Sustainable Use of Biodiversity (1995), which legally framed the importance of woodland in the country. Yukarigaoka also anticipated the Citizen Greenery Recognition Program developed as part of the 2017 revision of the Urban Green Space Act (Midori kakuho no sōgō-tekina hōshin) in Japan, that promotes "the maintenance of private green areas (e.g., satoyama woodlands and vacant lots in residential districts) through private sector initiatives (e.g., companies, NGOs, and neighborhood associations) instead of land owners" (Terada, 2017, p. 45). The local benefits of such initiatives are multifarious "including access to healthy food, food affordability, youth development and education, land stewardship" (Guitart et al., 2012).

In view of the aging Japanese society (a condition shared by many Asian countries) peripheral areas host great potential to retrofit communities closer to nature. The practices at play in Yukarigaoka provided a precedent for the 2017 revision of the City Planning Act (Toshi keikaku-hō) adopted Japan-wide, that focuses on the Garden Residential Zone, as a new addition to the national zoning regulation. This zone is "epoch-making as it deals for the first time with the urban-rural mixture in the context of urban planning" (Terada, 2017, p. 45) in its protection of existing farmland in residential districts and support for developments that integrate agriculture practices. This zoning regulation is relevant for fast-growing Asian cities, often characterized by laissez-faire urban-rural relationship.

From the point of view of place management, the role of Yukarigaoka's developer, Yamaman, has been crucial over the years, creating a clear vision for the town, ultimately achieving a defined identity. Concerning placebranding, Botschen et al. (2017, p. 158) highlight the "crucial prerequisite for the development of the intended brand identity lies in a core team with committed, empowered and - ideally - long-term secured key players of the particular place. [...] Often the initiator is one person", as is the case with Yamaman's founder.

Yamaman developed Yukarigaoka with a long-term profit motive, devising a tailored approach to land procurement, planning and management. As a result, the population has been increasing at a constant rate with a balanced demographic composition and low vacancy rates, in contrast to several publicly initiated projects throughout Japan. This has proven to be an astute business approach which provides a certain degree of stability and liveability to the development. As the company becomes more involved in stock management - with various sister companies addressing different aspects of urban management - Yamaman has been gradually devolving area management responsibilities to residents and neighborhood associations. From a developer's point of view, this is a way to share burdens and decrease costs while offering residents a degree of autonomy. In this respect, Yamaman's practice is in line with the current trend of Japanese urban planning, shifting its focus from "stock building" to "stock management” (Murayama, 2016).

In Japan, neighborhood associations play a prominent role and are the biggest civil society organization, whose membership is drawn from the local residential area, entailing the payment of a small monthly fee. These voluntary associations engage in various activities, bridging the gap between residents and local government. They are thus intermediaries, whose involvement is increasingly sought by "the state in systems that can manage collaboration, cooperation, compromise, and confrontation" (Pekkanen et al., 2014, p. 6). Yukarigaoka goes one step further in that it has expanded the scope of place management and has established processes to guarantee their effectiveness and long-term sustainability.

In view of an aging and shrinking population and cash-strapped municipalities, private neighborhood management is an increasingly popular form of localized governance, to the point that in the US privately-managed suburbs have become mainstream practice. Nevertheless, they can easily lead to the formation of gated communities, perceived as an aspirational form of living. We should therefore carefully distinguish between different types of private area management, as they can range from an effective form of devolved responsibility from the local government to residents, to segregated and deeply unsustainable enclaves for the well-to-do. While there are both detractors and proponents of private neighborhood management and associations, Yukarigaoka's example confirms that they can be "a major chance to innovate in governance” (Nelson, 2005, p. 13).

Based on our analyses, Yukarigaoka can be considered a case of sustainable peripheral development, in economic, social and environmental terms. Nevertheless, Yamaman's approach has a certain paternalistic trait, that has associations with the broader Japanese corporate and political culture. Moreover, Yamaman's board and personnel are not an elected body, creating a potential issue for the transparency and fairness of its management practices. Moreover, how long will this developer be involved in Yukarigaoka's urban management once the company's founder is gone? Yamaman seems to be aware of these issues and is gradually devolving more and new responsibilities to citizen-led groups. Whether this will, in turn, lead to compromises and incoherence in Yamaman's vision remains to be seen, and will have to be assessed in the future. 


\section{Conclusions}

Yukarigaoka provides important lessons for sustainable urban planning and place management. Specifically, it offers strategies to plan new communities and manage existing ones in the outskirts and peri-urban areas of many Asian cities (Sintusingha, 2006). Yukarigaoka is a model advocating for moderate growth different from speculative and fast-tracked developments we have come to associate with neoliberalism. Yet it is also far from "zero growth".

The approach, nonetheless, raises the following questions: from a local perspective, how would Yukarigaoka fare without the sustained guidance of Yamaman? Lacking a strong top-down framework, will machizukuri be able to build enough social capital in the future? Can local governments effectively refer to this developmental model? From a global perspective: are these culture-specific practices applicable to foreign contexts?

Japan is entering an era of "super-aging society", where shrinkage entails a fundamentally different urban paradigm as opposed to an era of growth. For one, Yamaman's practices broadly reflect the Japanese Developmental State: regulating the market while the state is "paternal to the people" (Tsukamoto, 2011, p. 84-85). The case study does imply a proactive role of private developers in offering alternatives to neoliberal practices that aim at high immediate returns. In Yukarigaoka, this drive was provided by a single individual envisioning a sustainable and livable town to be built in the span of four decades. This is hardly a transferable condition.

Yukarigaoka can nevertheless offer pragmatic lessons for contemporary and future suburban developments in the region, demonstrating unique spatial planning and place management practices that can be referred to, improved or tested in other contexts.

We would like to address here certain limitations to and future steps of this research: while the focus was on a single case study, the paper took a long-term view across four-decades, drawing comparisons with other new-city developments initiated in the same period in Japan and in the rest of the Asia-Pacific region. Our main interest has been on spatial planning and urban management. Future steps of this research shall focus on quantifying sustainability performances and look deeper into experiential aspects of livability, namely residents' perceptions of quality of life and their overall satisfaction.

A key contemporary housing issue that emerged from the case study is that of affordability, where Yukarigaoka has excelled. While this is not a principal focus of the paper and the Yukarigaoka case may be Japan-specific, Yamaman's management practices provide clues to how affordability can be achieved through intergenerational, integrated housing stock and demographic managementwhile still being profitable as a business model. The ability to successfully attract families with children, relative to their numerical decline in the rest of Sakura City and in Tama New Town, is testament to an attractive affordability/quality balance.
Lastly, the paper does not a-critically advocate for an "enlightened developer" model. While Yamaman is unique in various aspects, its strategies offer pertinent precedents regarding the integration of top-down and bottom-up implementation of planning and management, in a scenario where local governments and private area-management entities form alliances. Long-term, top-down guidance through the application of the triple-bottom line to develop and manage land and housing stocks acted as a driving force, complemented over the years with bottom-up community participation in place-making and branding, building social capital and enhancing liveability through the cultivation of a sense of ownership and identity. The case of Yukarigaoka provides significant evidence that this can be achieved at the scale of a suburban new city.

\section{References}

Aalbers, M. B. (2013). Neoliberalism is dead ... long live neoliberalism! International Journal of Urban and Regional Research, 37(3), 1083-1890. https://doi.org/10.1111/1468-2427.12065

Baliga, A., \& Chakrya, K. S. (2017, February 3). Boeung Kak: A disastrous decade. The Phnom Penh Post. https://www. phnompenhpost.com/national-post-depth-politics/boeungkak-disastrous-decade

Berghauser Pont, M., \& Haupt, P. (2010). Spacematrix: Space, density and urban form. NAi Publishers.

Boisen, M., Terlouw, K., Groote, P., \& Couwenberg, O. (2018). Reframing place promotion, place marketing, and place branding - moving beyond conceptual confusion. Cities, 80 , 4-11. https://doi.org/10.1016/j.cities.2017.08.021

Botschen, G., Promberger, K., \& Bernhart, J. (2017). Brand-driven identity development of places. Journal of Place Management and Development, 10(2), 152-172. https://doi.org/10.1108/JPMD-07-2016-0051

Brasor, P., \& Tsubuku, M. (2016, April 30). Yukarigaoka proves 'new towns' can age well. The Japan Times. http://www.japantimes.co.jp/community/2016/04/30/how-tos/yukarigaokaproves-new-towns-can-age-well/

Capitanio, M. (2018a). Participatory place management in the age of shrinkage: The case of Kunitachi within Tokyo's peripheral areas. Journal of Place Management and Development, 11(4), 447-462. https://doi.org/10.1108/JPMD-06-2017-0056

Capitanio, M. (2018b). The role of urban design in Tokyo's shrinking peripheral areas: The case of Tama New Town. Archnet-IJAR, 12(1), 112-133.

https://doi.org/10.26687/archnet-ijar.v12i1.1344

Du, H. (2015). Phu My Hung New Urban Development in Ho Chi Minh City: Only a partial success of a broader landscape. International Journal of Sustainable Built Environment, 4(1), 125-135. https://doi.org/10.1016/j.ijsbe.2015.03.005

Forsyth, A., \& Crewe, K. (2009). New visions for suburbia: Reassessing aesthetics and place-making in modernism, imageability and new urbanism. Journal of Urban Design, 14(4), 415-438. https://doi.org/10.1080/13574800903265470

Guitart, D. A., Pickering, C., \& Byrne, J. A. (2012). Past results and future directions in urban community gardens research. Urban Forestry \& Urban Greening, 11(4), 364-373. https://doi.org/10.1016/j.ufug.2012.06.007

Huynh, D. (2015). Phu My Hung New Urban Development in Ho Chi Minh City: Only a partial success of a broader landscape. 
International Journal of Sustainable Built Environment, 4(1), 125-135. https://doi.org/10.1016/j.ijsbe.2015.03.005

Insch, A., \& Florek, M. (2008). A great place to live, work and play. Journal of Place Management and Development, 1(2), 138-149. https://doi.org/10.1108/17538330810889970

Knox, P. L., \& Mayer, H. (2009). Small town sustainability: Economic, social, and environmental innovation (1 ed.). Birkhäuser Architecture. https://doi.org/10.1515/9783034608978

Kodama, S., \& Nakano, T. (2016). Yūkarigaoka kara kangaeru seichō kanri machi-dzukuri ni kansuru kenkyū.

Lee, C.-M., \& Stabin-Nesmith, B. (2001). The continuing value of a planned community: Radburn in the evolution of suburban development. Journal of Urban Design, 6(2), 151-184. https://doi.org/10.1080/13574800120057827

Murayama, A. (2016). Land use planning for depopulating and aging society in Japan. In Urban resilience (pp. 79-92). Springer International Publishing. https://doi.org/10.1007/978-3-319-39812-9_5

Motani, K. (2014). Shinayakana nipponrettō nokku Rikata. Satō takanobu, Tōkyō.

Nassauer, J. I. (1995). Messy ecosystems, orderly frames. Landscape Journal, 14(2), 161-170. https://doi.org/10.3368/lj.14.2.161

Nelson, R. H. (2005). Private neighborhoods and the transformation of local government (1st ed.). Rowman \& Littlefield Publishers.

Nihon Toshi Keikaku Gakkai. (2011). 60 Purojekuto ni yomu Nihon no toshi-dzukuri. Asakurashoten, Tōkyō.

Nikkei Keizai Shinbunsha. (2019). Genkai toshi, Anata no machi ga mushibamareru. Nihon Keizai shinbun shuppan, Tōkyō.

Pekkanen, R. J., Tsujinaka, Y., \& Yamamoto, H. (2014). Neighborhood associations and local governance in Japan (1 ed.). Routledge. https://doi.org/10.4324/9781315797731

Seki, Y., Kobayashi, S., \& Uchiumi, M. (2002). Study on the realities of area management led by private associations' Cases in Yukarigaoka District \& Usui District, Sakura City (in Japanese).
Sevtsuk, A. (2016). City form lab. http://cityform.mit.edu/en

Sintusingha, S. (2006). Sustainability and urban sprawl: Alternative scenarios for a Bangkok superblock. URBAN DESIGN International, 11(3), 151-172.

https://doi.org/10.1057/palgrave.udi.9000174

Sintusingha, S. (2008). Sustainable world-class cities and glocal sprawl in Southeast Asian metropolitans. In M. Jenks, D. Kozak, \& P. Takkanon (Eds.), 'World cities' and urban form: Fragmented, polycentric, sustainable? (pp. 145-160). Routledge.

Statistics Japan. (2018, February 7). Average residential land price. https://stats-japan.com/t/kiji/11139

Terada, T. (2017). Urban sprawl or co-existence with nature: Lessons from Japanese urban-rural mixture. In The 2017 IFLA Asia Pacific Regional Congress (pp. 41-49), Bangkok.

Tokyo Metropolitan Government. (2017). Tokyo's history, geography, and population. http://www.metro.tokyo.jp/ENGLISH/ ABOUT/HISTORY/history03.htm

Tsukamoto, T. (2011). Neoliberalization of the Developmental State: Tokyo's bottom-up politics and state rescaling in Japan. International Journal of Urban and Regional Research, 36(1), 71-89. https://doi.org/10.1111/j.1468-2427.2011.01057.x

Uemura, T. (2019). Discussion on the factors of sustainable urban growth in shrinking region: Case Study of Eucalyptus Hills in the city of Sakura developed by the private developer Yamaman. In The AESOP Annual Congress (pp. 4357-4379), Venice.

van den Hoek, J. W. (2008). The MXI (Mixed-Use Index) as tool for urban planning and analysis (No. 3, Delft). http://bk.home. tudelft.nl/fileadmin/Faculteit/BK/Actueel/Symposia_en_congressen/CRE_2008/Papers/doc/Paper03_vandenHoek.pdf

Yamaman Kabushikigaisha. (2016). Chitoseyūto Yūkarigaoka. Yume hyakka, 10(2). http://town.yukarigaoka.jp/news/wpcontent/uploads/2013/10/yume_10-02.pdf

Zenker, S., \& Rütter, N. (2014). Is satisfaction the key? The role of citizen satisfaction, place attachment and place brand attitude on positive citizenship behavior. Cities, 38, 11-17. https://doi.org/10.1016/j.cities.2013.12.009 